\title{
A GESTÃO DE PESSOAS NAS MICRO E PEQUENAS EMPRESAS: COMPARANDO EXPERIÊNCIAS
}

DOI: 1014211/Rege33189

Artigo recebido em:13/09/2014 Artigo aprovado em:18/09/2015

Laís Fernanda de Azevedo Silva - Universidade Federal do Rio Grande do Sul 1 Angela Beatriz Busato Scheffer - Universidade Federal do Rio Grande do Sul 2

Resumo: A gestão de pessoas é uma área que vem evoluindo ao longo do tempo e representa um constante desafio nas organizações. O Brasil apresenta um cenário no qual as atividades de comércio, produção e serviço das Micro e Pequenas Empresa (MPEs) são responsáveis por $60 \%$ da geração de empregos formais no país. Mesmo com a notória relevância das MPEs, a literatura acadêmica pouco aborda a gestão de pessoas nesse contexto e privilegia os modelos de gestão das grandes organizações. Portanto, o objetivo central deste trabalho é investigar a maneira com que tem sido construída e praticada a gestão de pessoas nos pequenos empreendimentos, bem como apresentar as experiências de profissionais que atuaram tanto em pequenas como em grandes empresas. Foram realizadas entrevistas com proprietários e gestores de MPEs de variados ramos e com pessoas que saíram de grandes empresas para trabalhar em micro ou pequenos negócios. Verificou-se a construção da gestão de pessoas pautada nas vivências e nas experiências de seus proprietários, a forte influência do paternalismo nas práticas, a presença de algumas ideias diferenciadas e um espaço valorizado de possibilidades para os que, oriundos das grandes empresas, escolhem as menores para fazerem suas carreiras.

Palavras-chave: Práticas de Gestão de Pessoas; Micro e Pequenas Empresas; Modelos.

\section{THE HUMAN RESOURCE MANAGEMENT IN SMALL BUSINESS: COMPARING EXPERIENCES}

Abstract: Human resource management is an area that has been developing through time and is a constant challenge in organizations. Brazil presents a scenario in which trade activities, production and service of Micro and Small Enterprises (SMEs) account for $60 \%$ of the generation of formal jobs in the country. Even with the notable relevance of SMEs, the academic literature barely discusses the human resource management in this context and focuses on management models of large

\footnotetext{
${ }^{1}$ Endereço: Rua Vitória, 107, apto. 105, Bairro Santana, Porto Alegre - RS, CEP: 90620-180. E-mail: laisf_azevedo@hotmail.com

${ }^{2}$ E-mail: angela.scheffer@ufrgs.br
}

SILVA, L. F. A.; SCHEFFER, A. B. B. A gestão de pessoas nas micro e pequenas empresas: comparando experiências. Revista de Empreendedorismo e Gestão de Pequenas

Empresas, v.4, n.3, 2015. 
corporations. Therefore, this paper aims to investigate the way that the human resource management has been built and practiced in SMEs enterprises, as well as presenting the work experience of professionals that acted both in small and big companies. Interviews were conducted with owners and managers of SMEs of various sectors and with professionals who came out of large corporations to work in micro or small business. It was verified that the construction of human resource management is based on the experiences of their owners, the strong influence of paternalism in their practices, the presence of some different ideas and a valued space of possibilities for those who come from big companies and choose the smallest to make their careers.

Keywords: Human Resource Management Practices; Micro and Small Business; Models.

\section{Introdução}

A gestão de pessoas (GP) é uma área que vem evoluindo ao longo da história da administração e representa um constante desafio nas organizações. Diante de uma economia crescentemente global, da emergência de uma sociedade do conhecimento e do aumento da complexidade das empresas, a gestão empresarial se modificou ao longo das últimas décadas (SANTOS, 2004).

Surge, então, a necessidade de se pensar em modelos capazes de abranger as demandas organizacionais de maneira sistemática. Nesse sentido, os modelos de gestão de pessoas precisam estar adequados para atrair, reter e desenvolver pessoas com capacidades desejadas e, ao mesmo tempo, alinhar-se às estratégias de negócio da organização (WOOD JUNIOR, 2004; LEGGE, 2005).

No Brasil, o movimento acelerado da industrialização trouxe uma preocupação com as práticas de gestão de pessoas nas empresas. Os princípios de divisão do trabalho, procedimentos de recrutamento, seleção, treinamento e desenvolvimento, tiveram suas bases fundadas nas grandes empresas norteamericanas e europeias.

As escolas de administração, juntamente com empresas de consultoria e a mídia, também tiveram importante papel para a disseminação dessas práticas no Brasil que, no entanto, continuam privilegiando o âmbito das grandes empresas e corporações, principalmente por seu tamanho e complexidade (WOOD JUNIOR, 2004).

SILVA, L. F. A.; SCHEFFER, A. B. B. A gestão de pessoas nas micro e pequenas empresas: comparando experiências. Revista de Empreendedorismo e Gestão de Pequenas

Empresas, v.4, n.3, 2015. 
Além disso, como apontam Ipiranga e Swirski (2012), a abrangência da produção do conhecimento na área de gestão de pessoas e relações de trabalho nem sempre implicou na construção de organizações melhores, no sentido de estarem mais bem preparadas para prover bem-estar para os seus diferentes públicos, sejam internos ou externos, bem como fornecer subsídios para que seja possível a renovação de modelos de gestão tendo em vista o contexto brasileiro de desenvolvimento social e econômico.

O Brasil apresenta um cenário no qual as atividades de comércio, produção e serviço das Micro e Pequenas Empresa (MPEs) são grandes impulsionadoras do PIB, além de serem responsáveis por $60 \%$ da geração de empregos formais no país (BRASIL, 2014). A notória relevância das MPEs faz com que se reflita a respeito da carência de literatura que as abrangem, passando a questionar o discurso de recursos humanos no Brasil que privilegia os modelos das grandes organizações.

Nessa linha, o objetivo deste estudo é investigar a maneira pela qual tem sido construída e praticada a gestão de pessoas nos pequenos empreendimentos, bem como apresentar as experiências de profissionais que atuaram tanto em pequenas como em grandes empresas.

Para entender de que modo a gestão de pessoas, as trajetórias e desafios enfrentados se constroem, foram realizadas 10 (dez) entrevistas com proprietários e gestores de micro e pequenas empresas de variados ramos. Outras 8 (oito) entrevistas foram realizadas com pessoas que saíram de grandes empresas para trabalharem em micro e pequenas empresas (por insatisfação ou por ambições pessoais de carreira, sendo que nenhuma delas foram demitidas por justa causa), com a finalidade de entender e comparar as práticas em termos de gestão de pessoas vivenciadas. Todas as entrevistas foram gravadas e transcritas para uma análise qualitativa dos depoimentos.

O trabalho está dividido em 6 (seis) seções incluindo esta introdução. Primeiro, fez-se um panorama geral da pequena empresa no contexto brasileiro e em seguida, uma revisão de literatura a respeito do tema de gestão de pessoas. $\mathrm{Na}$ quarta seção, detalhou-se a metodologia e o delineamento da pesquisa. $\mathrm{Na}$ sequência, é feita uma análise das entrevistas, evidenciando as práticas de gestão de pessoas nas pequenas empresas e o que as diferem das grandes empresas a 
partir do olhar dos entrevistados que tiveram ambas vivências. Por fim, chega-se a algumas considerações finais.

\section{A pequena empresa no contexto brasileiro}

A década de 1980 foi marcada pela desaceleração do ritmo de crescimento da economia brasileira e, como consequência, o aumento na taxa do desemprego, com queda no número de empregos formais e crescimento do setor informal como forma de complemento à renda familiar. Esse contexto proporcionou a emergência de pequenos negócios como alternativa à ocupação do excedente de mão de obra (IBGE, 2003; GOMES, 2002).

Ainda nesse período, algumas iniciativas surgiram para incentivar a abertura de pequenos empreendimentos, como o Primeiro Estatuto da Microempresa (Lei n7.256 de 27/11/1984) e também a inclusão das micro e pequenas empresas na Constituição Federal de 1988 (IBGE, 2003).

A partir de então, os empresários tiveram respaldos legislativos, institucionais e econômicos para estimularem os negócios. Segundo relatório do IBGE (2003), em 1990, o Centro Brasileiro de Assistência Gerencial à Pequena Empresa (CEBRAE), criado em 1972, foi transformado em Serviço Brasileiro de Apoio às Micro e Pequenas Empresas (SEBRAE), com funções mais amplas.

Além do SEBRAE, foram criadas linhas especiais de crédito no BNDES, Caixa Econômica Federal e Banco do Brasil. Instituiu-se o Sistema Integrado de Pagamentos de Impostos e Contribuições das Microempresas e das Empresas de Pequeno Porte (SIMPLES) e o Estatuto da Microempresa e da Empresa de Pequeno Porte em 1999. Foi estabelecido o Fórum Permanente das MPEs e criados vários programas federais de apoio ao pequeno empresário, dentre eles o PROGER (Programa de Geração de Emprego e Renda) e o Brasil Empreendedor, com capacitação para o empreendedor e assessoria empresarial da pequena empresa.

Atualmente, as atividades de comércio, produção e serviço das MPEs são grandes impulsionadoras do PIB brasileiro. De acordo com a última pesquisa do IBGE em 2001, foi revelado que $99 \%$ dos estabelecimentos formais do Brasil são 
constituídos por MPEs e são responsáveis por, aproximadamente, $60 \%$ dos empregos no país (BRASIL, 2014).

Em fevereiro de 2014, o SEBRAE divulgou um relatório que mostra que os pequenos negócios geraram 148.152 novos empregos celetistas, respondendo por $56,8 \%$ dos empregos formais registrados no país naquele mês, enquanto as médias e grandes empresas (MGEs) e a "Administração Pública" foram responsáveis, respectivamente, pela criação líquida de 99.867 e de 12.804 postos de trabalho.

O IBGE evidencia a relevância da pequena empresa para o Brasil:

Uma importante contribuição das micro e pequenas empresas no crescimento e desenvolvimento do País é a de servirem de "colchão" amortecedor do desemprego. Constituem uma alternativa de ocupação para uma pequena parcela da população que tem condição de desenvolver seu próprio negócio, e em uma alternativa de emprego formal ou informal, para uma grande parcela da força de trabalho excedente, em geral com pouca qualificação, que não encontra emprego nas empresas de maior porte (IBGE, 2003, p. 15).

Assim, pode-se observar que a importância da pequena empresa no país é notória, seja pela representatividade na economia, seja pelo expressivo montante de trabalhadores que emprega.

Entretanto, a literatura privilegia o estudo da grande empresa por seu tamanho e complexidade, sob a premissa que sua análise pode ser estendida ao pequeno negócio (LASTRES; CASSIOLATO; MACIEL, 2003).

Na próxima seção, é feita uma revisão de literatura em torno do tema de gestão de pessoas.

\section{A gestão de pessoas e suas práticas no Brasil}

A urbanização, a industrialização e a modernização marcaram as décadas de 1950 e 1980 no Brasil. Neste período, o processo de industrialização se tornou a principal maneira encontrada pelo governo para modernizar e aumentar a taxa de crescimento da economia do país (BAER, 1996).

SILVA, L. F. A.; SCHEFFER, A. B. B. A gestão de pessoas nas micro e pequenas empresas: comparando experiências. Revista de Empreendedorismo e Gestão de Pequenas

Empresas, v.4, n.3, 2015. 
A presença de multinacionais e o surgimento das escolas de administração tiveram importante papel na transformação da gestão nas empresas brasileiras. A necessidade de tornar as pessoas mais produtivas, oferecendo o melhor de si para o rendimento do trabalho, levou as organizações a investirem em uma área técnicocientífica, denominada de Administração de Recursos Humanos (ARHs) (WOOD JUNIOR; TONELLI; COOK, 2011; GOULART, 2002).

Segundo Wood Junior (2004), foi a partir da industrialização que as práticas de gestão de recursos humanos se estenderam para as empresas brasileiras. Os princípios de divisão do trabalho, procedimentos de recrutamento, seleção, treinamento e desenvolvimento tiveram suas bases nas empresas norte-americanas e europeias.

Para o autor, três foram os movimentos paralelos que motivaram a popularização de tais práticas: o crescimento da presença das empresas estrangeiras no país; a criação, consolidação e desenvolvimento das empresas estatais; e a formação de alguns grandes grupos nacionais. Entretanto, o desenvolvimento de gestão de pessoas se deu sem grandes rupturas e evoluções em termos de aplicação e adaptação.

A abertura econômica da década de 1990 trouxe grandes mudanças para a gestão das empresas brasileiras para concorrer com as multinacionais. Os empreendimentos buscaram desenvolver técnicas e práticas de gestão de pessoas cada vez mais modernas (TANURE; EVANS; CANÇADO, 2010). Além disso, essa mudança também foi caracterizada pela adoção de programas de redução de custos, revisões de portfólios de negócios e pela adoção de novas tecnologias de produção (WOOD JUNIOR et al., 2011).

O processo de reengenhariaz foi muito popular na época, muitas empresas promoveram cortes expressivos em seus quadros operacionais e gerenciais. Essas medidas de redução do número de funcionários, pouco a pouco, foram cedendo espaço para abordagens mais consistentes que buscavam alinhar iniciativas e

\footnotetext{
${ }^{3} \mathrm{De}$ acordo com Stair e Reynolds (2002, p. 39), reengenharia é o redesenho de processos, envolve a readequação dos processos empresariais, estruturas organizacionais, sistemas de informação e valores da organização objetivando uma guinada nos resultados dos negócios da organização.

STAIR, R. M.; REYNOLD, G. W. Sistemas de Informação nas Organizações. In: Princípios de sistemas de informação: uma nova abordagem gerencial. 4 ed. Rio de janeiro: LTC, 2002. p. $30-$ 58.
}

SILVA, L. F. A.; SCHEFFER, A. B. B. A gestão de pessoas nas micro e pequenas empresas: comparando experiências. Revista de Empreendedorismo e Gestão de Pequenas

Empresas, v.4, n.3, 2015. 
sistemas relacionados com o fator humano e às necessidades ditadas pelos negócios (WOOD JUNIOR, 2004). Assim, entrou em evidência, a chamada gestão estratégica de recursos humanos.

Legge (2005) define estratégia em três níveis:

[...] estratégia de primeira ordem, trabalhar a direção de longo prazo da empresa e o escopo de suas atividades, posicionamento de mercado, localizações e assim por diante, para o "negócio"; estratégia de segunda ordem, lidar com procedimentos operacionais internos e as relações entre as diferentes partes da organização, por meio de ações funcionais ou; estratégia de terceira ordem, que envolve funções diferentes, incluindo a gestão de recursos humanos, elaboração de estratégias amplas para apoiar o negócio e alcançar os objetivos de performance (LEGGE, 2005, p. 134).

Tomando-se por base a terceira ordem de estratégia destacada por Legge (2005), na qual as diferentes áreas da organização devem se envolver na elaboração de amplas estratégias para apoiar os objetivos finais do negócio, propõese a definição de gestão estratégica de pessoas como: todas as práticas, atos, ações e funções destinadas à gestão de pessoas, por parte não somente do setor de recursos humanos, mas por todos aqueles que de alguma forma devem gerir pessoas em suas equipes ou setor, que estejam planejadas, elaboradas e realizadas em sintonia com os objetivos de negócio da empresa.

No Brasil, de maneira geral, as empresas fazem uso de modelos de gestão de pessoas, sejam os disseminados e estratégicos modelos por competência, por desempenho ou até a gestão de talentos. Utilizam-se de cada um deles com seus pressupostos e referências.

Usualmente, as empresas buscam o alinhamento com as diretrizes estratégicas da organização para atrair, desenvolver e reter indivíduos com o perfil desejado. Valorizam a necessidade de trabalhadores mais responsivos, capazes de gerir sua própria carreira, empreendedores de si mesmos, que busquem autoconhecimento, capazes de aprenderem continuamente, bem como de uma organização que deve ser cada vez mais enxuta (FREITAG; OHTSUKI; FERREIRA, 2012).

SILVA, L. F. A.; SCHEFFER, A. B. B. A gestão de pessoas nas micro e pequenas empresas: comparando experiências. Revista de Empreendedorismo e Gestão de Pequenas

Empresas, v.4, n.3, 2015. 
Nas pequenas e médias organizações, o uso desses modelos disseminados nem sempre é a melhor opção para a gestão, dado o seu pequeno porte e número reduzido de funcionários. Para Gonçalves e Koprowski (1995), as pequenas empresas são caracterizadas pela forte presença do proprietário ou de seus familiares à frente da gestão do negócio, pela ausência de administração especializada fora da empresa, pela estreita relação pessoal do proprietário com os empregados, clientes e fornecedores, e também pela sua direção pouco especializada.

Nesse mesmo sentido, Marlow e Patton (1993) afirmam que as culturas dos micro e pequenos empreendimentos são moldadas, pelo menos inicialmente, por proprietários cujos objetivos e desejos são comunicados diretamente aos empregados, em um contexto de proximidade espacial e social, promovendo relacionamentos e práticas de trabalho informais. Essas práticas acabam por se tornar rapidamente adaptáveis em contexto de mudança.

Assim, segundo os referidos autores, os conceitos desenvolvidos para entender as relações de trabalho nas grandes empresas não são, em grande parte, aplicáveis às pequenas empresas. Desse modo, torna-se incomum a adoção de modelos de gestão por empresas de micro e pequeno porte.

Por modelos de gestão de pessoas, entende-se a maneira pela qual uma empresa ou seus gestores se organizam para gerenciar e orientar o comportamento humano no trabalho. Para tanto, são definidos princípios, estratégias, políticas e práticas para a gestão. Então, é correto dizer que tudo aquilo que interfere de alguma maneira nas relações organizacionais pode ser considerado um modelo (FISCHER, 2002).

Nas pequenas empresas, percebe-se que os modelos de gestão de pessoas consideram a dinâmica própria vivenciada, sendo produzidos e exercitados a partir de um conjunto de práticas que se dão muito no cotidiano de trabalho.

Como se depreende, entende-se as práticas de gestão de pessoas nos pequenos empreendimentos como práticas cotidianas que, embora se constituam enquanto um saber próprio, não estão estruturadas em discurso formal ou procedimentos racionalizados, nem ao menos conta com a fixidez repetitiva dos ritos, lembrando o conceito de Certeau (1998).

SILVA, L. F. A.; SCHEFFER, A. B. B. A gestão de pessoas nas micro e pequenas empresas: comparando experiências. Revista de Empreendedorismo e Gestão de Pequenas

Empresas, v.4, n.3, 2015. 
Conforme evidenciado por Barros et al. (2011), costuma-se negligenciar muitos conhecimentos por não considerá-los valorosos. Estes conhecimentos são transmitidos em relações estabelecidas a partir de lógicas diferentes e que circulam em virtude de laços familiares ou afetivos adquiridos, construídos e significados na cotidianidade. Como exemplo, pode-se citar o caso dos saberes do pequeno comerciante ou do comerciante individual que "estão entre as várias questões 'esquecidas' pelo saber técnico-científico empregado e/ou gerado na administração, sendo, em geral, considerados de pouca importância e comumente desprezados" (BARROS et al., 2011, p. 46).

De acordo com Ram (1999) e Cardon e Stevens (2004), quando se fala sobre relações de trabalho em micro e pequenas empresas, é necessário que se lance um olhar mais abrangente sobre como tais empresas contratam, gerenciam, preparam, recompensam e lidam com disputas e conflitos entre os seus funcionários, bem como a relação mais ampla entre os empregados e os empregadores.

Cardon e Stevens (2004) afirmam que faltam abordagens e dados que permitam compreender a gestão de pessoas nas MPEs, visto que estas organizações nem sempre possuem mapeadas as funções e estratégias da gestão de pessoas, mesmo que se tenha por base teorias vigentes de gestão de pessoas provenientes de pesquisas em grandes empresas.

Neste ponto é importante compreender as teorias e os modelos de gestão de pessoas enquanto estratégia para uma organização e como se dá a construção das relações de gestão e de trabalho operadas nas MPEs. Para tanto, buscou-se refletir sobre a gestão de pessoas no pequeno negócio, contrapondo-se ao discurso privilegiado de modelos de GP no Brasil, tendo como base os modelos das grandes organizações. Buscou-se, ainda, entender os significados da gestão de pessoas, como é pensada e praticada, tendo em vista as circunstâncias em que ocorrem e o contexto que a ocasionou.

SILVA, L. F. A.; SCHEFFER, A. B. B. A gestão de pessoas nas micro e pequenas empresas: comparando experiências. Revista de Empreendedorismo e Gestão de Pequenas

Empresas, v.4, n.3, 2015. 


\section{Procedimentos metodológicos}

A definição de "pequena empresa" depende das fontes utilizadas, dos dados disponíveis, das escolhas a serem feitas e da interpretação do pesquisador (LASTRES; CASSIOLATO; MACIEL, 2003).

Apesar das diversas abordagens e classificações existentes, este trabalho utilizou a classificação de empresas de acordo com o número de funcionários do SEBRAE (2013), visto que a quantidade de pessoas existentes em uma organização influencia diretamente o trabalho gerencial. Isto vem de encontro com o objetivo do trabalho, no que diz respeito à gestão de pessoas.

Quadro 1 - Definição de MPEs de acordo com o Número de Empregados

\begin{tabular}{|l|c|c|}
\hline \multicolumn{1}{|c|}{ Porte/Setor } & Indústria & Comércio e Serviço \\
\hline Microempresas & Até 19 & Até 9 empregados \\
\hline Empresas de PP & De 20 a 99 & De 10 a 49 \\
\hline Médias & De 100 a 499 & De 50 a 99 \\
\hline Grandes & 500 ou mais & 100 ou mais \\
\hline
\end{tabular}

Fonte: SEBRAE (2013).

A metodologia utilizada é de natureza qualitativa, pois se caracteriza por buscar uma apreensão de significados na fala dos sujeitos, interligada ao contexto em que eles se inserem (ALVES; SILVA, 1992).

Foram realizadas dez (10) entrevistas de forma individual com gestores/proprietários de empresas de diferentes ramos, baseadas em um roteiro semiestruturado no qual não são fornecidas opções de resposta para não limitar ou direcionar a resposta do entrevistado. Todas as empresas possuíam até cinquenta (50) funcionários, o que as classificam como micro e pequenas empresas, seja no setor de indústria ou no setor de comércio e serviço.

As entrevistas foram gravadas e transcritas para uma análise qualitativa do discurso dos entrevistados. O conteúdo das entrevistas são sobre temas que envolveram a história da empresa, organização dos setores, busca de informações 
para uma melhor administração do negócio, gestão de pessoas e perspectivas futuras da empresa.

Além das entrevistas com o os proprietários/gerentes das empresas, foram realizadas, pelo mesmo procedimento, oito (8) entrevistas com pessoas que saíram de grandes empresas para trabalharem em pequenos negócios, sendo que nenhuma foi demitida, mas tiveram suas trajetórias guiadas por insatisfação ou ambições de carreira. Essas entrevistas tiveram por objetivo analisar e comparar as diferenças no campo da gestão de pessoas que tais funcionários puderam vivenciar por estarem em duas realidades diferentes.

Assim, buscou-se, a partir de uma leitura flutuante, apreender as ideias principais e os seus significados gerais. Primeiro, estabeleceu-se o elemento básico de análise: a gestão de pessoas e suas formas na micro e pequena empresa. Em seguida, foram elencadas as categorias para a análise: construindo os saberes em gestão de pessoas, as práticas de gestão de pessoas (seleção e remuneração), gerenciando pessoas e comparando a gestão de pessoas nas pequenas e grandes empresas (experiências).

Quadro 2- Lista com os setores das empresas selecionadas para a realização da pesquisa, função exercida pelo entrevistado na empresa e a classificação de acordo com o número de funcionários.

\begin{tabular}{|l|c|c|}
\hline \multicolumn{1}{|c|}{ Setor } & Função & Porte da Empresa - No Funcionários \\
\hline Consultoria & Sócio Proprietário & Pequena Empresa - 25 funcionários \\
\hline Restaurante & Sócio Proprietário & Pequena Empresa - 14 funcionários \\
\hline Restaurante & Proprietário & Pequena Empresa - 12 funcionários \\
\hline Restaurante & Sócio Proprietário & Pequena Empresa - 27 funcionários \\
\hline Padaria & Proprietário & Microempresa - 7 funcionários \\
\hline Padaria & Proprietário & Pequena Empresa - 12 funcionários \\
\hline Padaria & Proprietário & Pequena Empresa - 14 funcionários \\
\hline Confecção & Proprietário & Pequena Empresa - 40 funcionários \\
\hline Distribuição de Aço & Gerente Comercial & Pequena Empresa - 30 funcionários \\
\hline Produção de Torneiras & Proprietário & Microempresa - 18 funcionários \\
\hline
\end{tabular}

Fonte: As autoras (2015).

SILVA, L. F. A.; SCHEFFER, A. B. B. A gestão de pessoas nas micro e pequenas empresas: comparando experiências. Revista de Empreendedorismo e Gestão de Pequenas

Empresas, v.4, n.3, 2015. 
Quadro 3 - Relação da função exercida pelos entrevistados que saíram de grandes empresas para trabalharem em pequenas empresas e tempo de atuação na organização

\begin{tabular}{|c|c|}
\hline Função & Tempo na Grande Empresa (anos) \\
\hline Operador & 17 \\
\hline Chefe de Vendas & 12 \\
\hline Vendedor & 10 \\
\hline Assistente Administrativo & 8 \\
\hline Vendedor & 4 \\
\hline Engenheiro de Processo & 3 \\
\hline Coordenador de PCP & 3 \\
\hline Coordenador de projeto & 2 \\
\hline
\end{tabular}

Fonte: As autoras (2015).

\section{Evidências da gestão de pessoas - construindo os conhecimentos em gestão de pessoas}

Os entrevistados, de maneira unânime, ressaltaram a experiência, a prática, como principal balizador na condução de seus negócios. Em várias situações, o profissional do pequeno empreendimento traz a vivência de empregos anteriores para aplicação na sua empresa, ou ainda, a vasta aprendizagem por longos anos de sobrevivência da firma naquele ramo.

Um dos entrevistados evidenciou: "a empresa que eu trabalhava me ensinou muito como fazer, mas também como não fazer". Como se observa, ele revela que as vivências dos indivíduos são fenômenos da cultura e da construção social passada, influenciando a formação de seus saberes administrativos. Isto evidencia a prática e o aprendizado como importantes mecanismos de direcionamento da gestão.

Além da experiência, como meios de atualização profissional, foram ressaltados: busca de assistência ao SEBRAE, procura de cursos para a capacitação dos funcionários através do SENAC (Serviço Nacional de Aprendizagem Comercial), assinatura de revistas e sites especializados, associações comerciais, coachings, rede de contatos (network) com concorrentes, 
fornecedores e profissionais de outros ramos, e, em última instância, cursos de MBA e pós-graduação.

Este cenário de aprendizado indica que meios especializados são mais condizentes com a realidade dos pequenos negócios, dado o seu caráter específico, por vezes personalizado, de atendimento ao demandante. Quando questionados a respeito da produção científica como meio de informação e capacitação, os entrevistados, novamente, ressaltaram a preferência pela experiência e vivência de mercado à capacitação formal por meio de pós-graduações ou MBAs (Master Business Administration), e mostraram dificuldade de compreensão e acesso aos trabalhos acadêmicos.

[...] minha capacitação é muito mais informal do que formal hoje, porque pra mim, é muito mais valioso eu passar uma tarde com um grande fornecedor, e entender ele, qual é a sua visão para o mercado, do que estar dentro de uma sala de aula [...] O pequeno empresário quando vai buscar informação tem dificuldades de encontrar soluções para pequena empresa, as informações disponíveis são de grandes empresas e eles acabam por não conseguir adequar esses estudos às suas realidades (ENTREVISTA, proprietário da empresa de confecção).

Segundo Barros et al. (2011), especificamente dentro do meio acadêmico, observa-se a predileção por saberes produzidos em outros países em detrimento da produção acadêmica brasileira. Da mesma forma, este movimento demarca uma superioridade das formas de gerir grandes empresas, em comparação às utilizadas na gestão de micro e pequenas empresas.

Nesse sentido, percebe-se que a gestão nessas empresas (MPEs), assim como a gestão de pessoas, é muito mais construída na prática, a partir de acertos e erros, de relacionamentos, de experimentação, de construções sociais, experiências vividas e enfrentamento do cotidiano, do que a partir de cursos acadêmicos, reflexões teóricas ou saberes científicos.

\section{As práticas de gestão de pessoas - a seleção}

A função de recrutamento e seleção dentro das empresas é uma atividade direcionada à área de gestão de pessoas, comumente denominada pelos 
empresários de "recursos humanos", sendo composta por políticas que determinam quem irá trabalhar na organização. O recrutamento representa a porta de entrada das pessoas na empresa.

Longe de processos complexos, os empresários dos micro e pequenos empreendimentos procuram agir de forma a encontrar a pessoa adequada por meios mais rápidos, baratos e que lhes inspirem confiança. Portais de emprego, anúncios em jornais, agências de recrutamento, divulgação no site da empresa e em páginas de redes sociais, parceria com instituições de Ensino Superior e até mesmo indicações de funcionários e de clientes, foram as formas de recrutamento de profissionais que os participantes citaram.

Depois desse primeiro processo, a seleção de pessoas é dada através da entrevista dos candidatos pelo proprietário ou gestor da área. A entrevista é mais uma conversa informal para sentir a determinação e o comprometimento do candidato com o trabalho. O entrevistado do setor de confecções evidenciou que:

[...] eu quero ter gente comigo que queira crescer na vida, em todos os sentidos. Aprenda a ser um cidadão melhor, aprenda ser uma pessoa de família melhor. Uma coisa que a empresa que eu trabalhei me ensinou um pouco foi a questão de pensar nos outros, na sociedade onde você está, na comunidade que você está e que impactos você traz. É só o impacto de empregar a mão de obra, usar aquela mão de obra e ganhar dinheiro? Eu não quero isso, eu quero que aquela comunidade onde eu atuo também cresça e se desenvolva, e se eu puder contribuir de alguma forma vai ser excelente. E é o que a gente faz, nós estamos ali no Cidade Alta (bairro), a gente procura pegar pessoas dali. O processo de seleção é boca a boca, marca a entrevista, verificamos se a pessoa se enquadra nos valores da empresa - às vezes a pessoa não sabe nada, mas se enquadra nos nossos valores (ENTREVISTA, proprietário da empresa de confecção).

Por meio do depoimento acima, pode-se verificar a informalidade, a busca por pessoas dispostas e comprometidas com grandes competências e qualidades. A empresa está disposta a proporcionar o desenvolvimento profissional do indivíduo e procura por pessoas fiéis, que cresçam com o negócio.

Ainda que os processos de seleção sejam informais e simplistas, 9 (nove) dos 10 (dez) entrevistados disseram buscar funcionários que se enquadrem com os valores de seus estabelecimentos. É preciso dizer que o fato de a entrevista ser feita 
pelos próprios empreendedores, possibilita sentirem "olho no olho" a intenção, necessidade e motivação do candidato. Tem-se aqui o sentir, o feeling, que em processos do mainstream dos estudos organizacionais, são entendidos como saberes "irracionais" (que precisam ser racionalizados) ou não elaborados, ou até tidos como marginais no sentido de pouco importantes.

Nesses saberes levantados no estudo, há aspectos específicos de uma realidade, de uma lógica subjetiva, de uma construção de práticas pautadas na vivência e na intuição. Como afirma Barros et al. (2011), esses saberes são denominados "práticos" por não se adequarem às normas de produção da ciência ou da técnica e, muitas vezes, são tratados de forma pejorativa. Entretanto, foram esses saberes "práticos" que deram origem às teorias administrativas.

Ainda que muitas dessas práticas já estejam formalizadas, percebe-se uma continuidade, por parte dos entrevistados, no comportamento usual da cotidianidade como guia da administração e gestão de pessoas em seus empreendimentos.

\section{As práticas de gestão de pessoas - remuneração e benefícios}

Na maioria das vezes, o salário tem sido o principal elo entre empresários e empregados. Para estes, o salário significa subsistência, padrão de vida e reconhecimento. Para os empresários, representa um dos principais custos, fator influenciador do clima organizacional e da produtividade. Além dos salários, o pacote de benefícios busca agregar à remuneração, visando adicionar valores sociais e melhores condições para os funcionários, tanto no que tange os aspectos fisiológicos quanto psicológicos (ALVIM; ALVIM, 2011).

Sobre este item, todos os entrevistados alegaram pagar um montante compatível ao do mercado dentro das determinadas funções que possuem. Apenas o entrevistado do setor de confecções disse pagar acima de seus concorrentes no intuito de reter seus funcionários e fazer com que se desenvolvam junto à empresa, evitando a rotatividade.

Entretanto, nenhuma das empresas apresenta um plano de administração de cargos e salários definido, apenas um piso salarial para cada função dentro do

SILVA, L. F. A.; SCHEFFER, A. B. B. A gestão de pessoas nas micro e pequenas empresas: comparando experiências. Revista de Empreendedorismo e Gestão de Pequenas

Empresas, v.4, n.3, 2015. 
negócio, sendo que os reajustes vão sendo feitos, principalmente, via exigência do sindicato.

A empresa que mais se aproximou de um plano de remuneração foi a do ramo de consultoria. Ela faz reajustes anuais regulares além daqueles previstos pelo sindicato. O gestor da empresa de distribuição de aço mencionou que implantará um sistema de cargos e salários em breve, pois na atual situação, encontra grande dificuldade de reter funcionários pelo fato de não possuírem uma política regular de remuneração.

Em se tratando de benefícios, sete dos dez entrevistados buscam oferecer diversos subsídios para que seus funcionários se sintam valorizados e motivados.

A seguir, apresenta-se um quadro com as práticas citadas.

Quadro 4-Benefícios oferecidos pelas micro e pequenas empresas

\begin{tabular}{|c|c|}
\hline Empresa & Benefícios \\
\hline Consultoria & $\begin{array}{c}\text { Treinamento interno; Treinamento externo; Vale transporte; Vale } \\
\text { alimentação; Plano de saúde. }\end{array}$ \\
\hline Restaurante 14 func. & $\begin{array}{l}\text { Vale Transporte; Refeição no local; Bônus de acordo com o movimento de } \\
\text { clientes; Aula de Yôga; Compras direto com o fornecedor por um preço } \\
\text { menor; confraternizações. }\end{array}$ \\
\hline Restaurante 12 func. & $\begin{array}{l}\text { Horário flexível; Vale Transporte; Almoço no local; } 30 \% \text { de incremento na } \\
\text { hora extra. }\end{array}$ \\
\hline Restaurante 27 func. & $\begin{array}{l}\text { Plano de Saúde; Cesta Básica; Oficinas de música, dança e aulas de } \\
\text { inglês; confraternizações. }\end{array}$ \\
\hline Padaria 7 func. & Não mencionou \\
\hline Padaria 12 func. & Não mencionou \\
\hline Padaria 14 func. & Não mencionou \\
\hline Confecção & Plano de saúde; Folgas aleatórias; Comissão. \\
\hline Distribuição de Aço & $\begin{array}{l}\text { Plano de Saúde; Vale Alimentação; Alimentação no Local; Vale } \\
\text { Transporte; Seguro de Vida. }\end{array}$ \\
\hline Produção de Torneiras & Cesta Básica \\
\hline
\end{tabular}

Fonte: As autoras (2015)

A remuneração pode ser classificada em direta e indireta. A direta é o valor do salário e a indireta, os benefícios sociais. Por sua vez, se levado em consideração o objetivo dos benefícios sociais, estes podem ser classificados em assistenciais (condições de segurança e previdência em casos de imprevistos ou SILVA, L. F. A.; SCHEFFER, A. B. B. A gestão de pessoas nas micro e pequenas empresas: comparando experiências. Revista de Empreendedorismo e Gestão de Pequenas Empresas, v.4, n.3, 2015. 
emergências) ou recreativos/supletivos (condições de diversão, recreação, higiene mental, repouso ou lazer recreativo) (ALVIM; ALVIM, 2011).

Além de benefícios assistenciais, os empresários entrevistados pensaram e formularam a gestão de pessoas de seus empreendimentos em prol do bem-estar do indivíduo. Diante da dificuldade de reter pessoas, práticas como aulas de Yôga, dança, inglês, música e confraternizações, se tornaram ferramentas para incentivar, motivar e familiarizar o funcionário ao ambiente de trabalho, e mais do que isso, uma estratégia de gestão de pessoas para fortalecer a relação da organização com o indivíduo.

Sendo assim, percebe-se que hoje alguns benefícios diferenciais fazem parte das políticas de gestão de pessoas das pequenas empresas. Dentre suas diversas funcionalidades e categorias, os entrevistados mencionaram que por meio dessas práticas estratégicas conseguem, muitas vezes, manter os funcionários mais satisfeitos, motivados e comprometidos com a empresa.

A preocupação em manter o funcionário satisfeito e comprometido com os negócios da organização reflete a importância do empregado para o sucesso das MPEs, confirmando a ideia de Marlow e Patton (1993), que enfatizam a contribuição do trabalhador para este fim. Muitas vezes, essa condição é desvalorizada pela literatura, reforçando a relevância e a necessidade de se manter uma gestão efetiva quanto à relação empregado-empregador.

\section{Gerenciando pessoas}

A taxa de emprego formal registrada pela RAIS/CAGED do Ministério do Trabalho do Brasil, no fechamento de 2013, foi de 48,95 milhões de empregos. Acompanhando essa conjuntura, o Brasil apresentou uma taxa de rotatividade de empregados de 2,69 milhões de pessoas (BRASIL, 2014).

Tomando por base a rotatividade de pessoas nos mais variados setores, a gestão de pessoas se depara com diversos problemas. Ao mesmo tempo que busca a colaboração, o desenvolvimento, o resultado e a satisfação do trabalhador, tem de 
enfrentar resistências, sabotagens, greves e manipulações (TONELLI; PLIOPAS; FONSECA, 2005).

Por meio da análise de todas as 10 (dez) entrevistas, pode-se inferir que seus negócios são baseados, de certa forma, em uma versão mais soft da administração de recursos humanos, por entender: importância que o funcionário representa para o seu negócio; a dificuldade concorrencial enfrentada na seleção de pessoas; e a flexibilidade permeada entre indivíduo e proprietário.

Diante de problemas comportamentais, os proprietários e gestores nunca tomam decisões precipitadas. A primeira medida é a conversa franca com o funcionário. Isto demonstra a visão de que o indivíduo contratado representa uma peça fundamental para o negócio, refletindo o contexto atual em que prevalece a dificuldade de se encontrar novos empregados.

$\mathrm{Na}$ visão do dono da padaria, com 12 (doze) funcionários, a vantagem de administrar uma empresa com poucas pessoas é apresentada a seguir:

Eu acho que uma das possibilidades da pequena empresa é de tu conseguir administrar uma pessoa por vez, uma por uma. Tu tem a oportunidade de conhecer todas as necessidades de cada um dos teus funcionários. Dessa forma, é mais fácil de pegar onde estimula, porque tu sabe quais são as necessidades deles (ENTREVISTA, proprietário padaria 12 funcionários).

Nesse depoimento, assim como em outros semelhantes, identifica-se uma postura voltada para uma gestão mais individualizada. $O$ gestor comercial da empresa de distribuição de aço também relata a visão soft do proprietário, dessa vez destacando interesses também organizacionais:

Com as pessoas ele procurava entender o que estava acontecendo e colocava a posição da empresa perante aquela situação. E comigo ele mostrava, em algumas vezes, o caminho melhor de tratar aquele problema ou aquele tipo de situação (ENTREVISTA, gestor comercial empresa de distribuição de aço).

Somente após conversas e observações de mudanças é que medidas mais duras são tomadas. Para o dono da empresa de confecção: 
A demissão não é de uma hora pra outra, você vai analisando até você chegar a um ponto. Porque assim, não são situações pontuais, já tive situações de discussões acaloradas, de a pessoa me ligar e falar: vem pra cá porque tem uma costureira com a outra, que daqui a pouco elas vão se pegar no tapa aqui dentro. Então, você conversa, você trabalha e você já vê que aquela pessoa tem, de repente, uma personalidade mais inflamada, e a gente procura trabalhar, e já conseguimos melhorar muito nosso ambiente de trabalho com relação a isso (ENTREVISTA, proprietário empresa de confecção).

Todos os entrevistados, de alguma forma, citaram que a proximidade com o funcionário facilita a administração e condução dos negócios, bem como a gestão de pessoas. As práticas giram em torno de relações mais próximas, que são valorizadas para o alcance do desejado no trabalho. $O$ que é desafio em termos de gestão, o novo, o "desconhecido" - no sentido de não discutido no conhecimento sobre administração que tem suas bases nas grandes empresas - procura se tornar mais apropriado, tendo como base o familiar, ou seja, as relações mais pessoais, a história vivida pelos atores, os valores e intenções que guiam suas ações.

Outro ponto a ser destacado é que a questão sobre gestão de pessoas, geralmente, através dos depoimentos coletados, é trazida para o campo das relações de trabalho/relações de emprego. Ou seja, há uma preocupação em gerir com base naquilo que seja capaz de conectar as relações em seus contextos, minimizando os conflitos em torno da busca de algo que seja comum. Em função do tamanho das organizações, todos são considerados valiosos.

Assim, criam-se estilos de gestão mais próximos de um paternalismo sofisticado, pautado em canais mais próximos de comunicação, com expectativas de criação de uma responsabilidade mais autônoma, embora, como defina Legge (2005), as tipologias hoje existentes quanto a estilos de gestão sejam questionáveis por suas bases ou contextos de referência.

\section{Comparando a gestão de pessoas nas pequenas e grandes empresas - experiências}

Muitas vezes, nas grandes empresas, devido a tamanhos e complexidades, a gestão de pessoas falha no monitoramento e reconhecimento dos funcionários. SILVA, L. F. A.; SCHEFFER, A. B. B. A gestão de pessoas nas micro e pequenas empresas: comparando experiências. Revista de Empreendedorismo e Gestão de Pequenas Empresas, v.4, n.3, 2015. 
Além disso, muitas ações dentro dessas organizações demonstram o descolamento ou divergência entre discurso e prática.

Por tal razão, pode-se questionar o grau efetivo de contribuição das práticas de gestão de pessoas para o negócio, satisfação e motivação do trabalhador. Todos os 8 (oito) entrevistados encontraram um maior conforto e satisfação em trabalhar na pequena empresa, seja na execução do trabalho ou no novo modo de condução da vida pessoal.

Sobre a gestão de pessoas dentro das grandes organizações, foi unânime o discurso evidenciando que o setor de recursos humanos é muito distante do trabalhador, não havendo de fato um acompanhamento do trabalho realizado. $A$ progressão da carreira depende mais do superior imediato do que das políticas de recursos humanos em si.

O vendedor (4 anos de empresa) de uma multinacional que era pleiteado a ocupar um cargo executivo diz:

Eu estava sendo preparado para me tornar um gestor. E meu gerente imediato me valoriza muito, não que a empresa como um todo não valorizasse os funcionários, acontece que era muita gente e acaba sendo algo desigual. Se o seu gestor direto não conseguir fazer uma gestão diferenciada, a empresa por si só não faz, o setor de $\mathrm{RH}$ não consegue chegar em todas as pontas. São muitas pessoas, é você e um universo de mais mil indivíduos potenciais. Quando eu mudei de área, mudou meu gerente imediato e minhas chances de crescimento se reduziram demais. Meu antigo superior me dizia que em cinco anos eu chegaria a gerência de uma unidade, e o meu segundo gestor dizia que isso era muito pouco tempo, que meu desenvolvimento era de 7 a 10 anos, que na verdade esse foi 0 tempo que ele levou. Isso me desanimou muito. Foi quando surgiu uma oportunidade de trabalho nessa empresa menor (ENTREVISTA, vendedor 4 anos de empresa).

Dos 8 (oito) entrevistados, 6 (seis) relataram problemas com oportunidades limitadas pelo gestor imediato, sendo que 5 (cinco) disseram ser esse o principal motivo de demissão, relatando que a política de competências não foi eficaz na progressão das suas carreiras.

Além do caso relatado acima, o depoimento do vendedor (10 anos de empresa) mostra que a avaliação das competências foi adequada no que diz 
respeito à área de trabalho designada, entretanto, falhou quanto a prospecção de carreira:

Eu passei por três setores, logística, administrativo e vendas. O meu primeiro gerente achou que eu me daria bem na área porque eu era comunicativo, extrovertido e tinha um ótimo relacionamento com as pessoas. Em vendas eu encabecei um projeto que a empresa vendia 30 unidades daquele produto, quando eu saí a gente estava vendendo em torno de 800 unidades, o que me colocou muita perspectiva na empresa, a área cresceu pelo meu trabalho e de um colega [...]. Tive uma decepção muito grande que quando surgiu a oportunidade de assumir a chefia de vendas daquele produto/segmento que, praticamente, eu e o 'Fulano' fizemos crescer, ele já não estava mais na empresa, colocaram uma trainee e ainda me pediram para ensinar todo o trabalho para ela, afinal ela não tinha qualquer experiência na área de vendas. Eu entendo que a empresa investe muito na condição de trainee, mas essas pessoas são alocadas em cargos estratégicos sem a devida experiência, e acabam limitando o crescimento das pessoas daquela unidade. Esse foi o principal motivo que eu saí (ENTREVISTA, vendedor 10 anos de empresa).

O engenheiro de processos apresenta um relato que, além da falha na alocação de cargos, demonstra falha na política salarial da empresa. Com exceção às exigências sindicais, o aumento salarial provinha, na maioria das vezes, por meio da solicitação e cobrança do funcionário.

Eu não tinha perspectivas de crescimento, como eu não reclamava do salário eles se acomodaram e me mantiveram na função com o salário baixo. Minha função era bastante complicada porque mudava de turno toda hora, e ninguém queria fazer aquilo. Quando surgiu uma vaga de coordenador, que era a proposta inicial quando fui contratado, colocaram uma pessoa com menos experiência que eu, mas que estava perto do chefe do departamento, e eu fiquei ali, e ao meu redor só tinha peão, meu gerente raramente aparecia na área. Depois que eu disse que queria sair eles propuseram um aumento, até mudança de cargo, mas aí eu já estava desanimado e arrumei um emprego numa cidade menor, o salário não era mais alto, mas meus gastos eram muito menores (ENTREVISTA, engenheiro de processos 3 anos de empresa).

operador de pátio de uma multinacional relatou que entrou na empresa praticamente quando a filial se instalou na cidade. Entrou como ajudante de pátio e se desenvolveu junto com a empresa. Sua ambição era ser líder operacional. Tudo indicava e se encaminhava para isso. Quando o principal responsável pelo setor SILVA, L. F. A.; SCHEFFER, A. B. B. A gestão de pessoas nas micro e pequenas empresas: comparando experiências. Revista de Empreendedorismo e Gestão de Pequenas Empresas, v.4, n.3, 2015. 
entrava em férias, era ele que assumia todo o setor. Chegou a chefiar um dos turnos operantes da empresa, mas nunca foi promovido a líder operacional.

Quando o líder de pátio saiu da organização, o gerente responsável pela filial abriu um processo seletivo interno para o cargo, os próprios funcionários da área se recusaram a participar, visto que tinham respeito e consciência que aquela função deveria ser assumida pelo operador em questão. Diante da situação, o operador sofreu vários traumas psicológicos e após dezessete anos de serviço, pediu a demissão.

Três dos entrevistados abordaram motivos de demissão como pressão por desempenho, estresse elevado, acúmulo de tarefas, processos burocráticos e remuneração insatisfatória. A coordenadora de Planejamento e Controle de Produção (PCP), que trabalhava há 4 (quatro) anos na empresa, chegou a dizer que:

[...] eu nunca conseguia dormir antes das onze horas da noite, enquanto o segundo turno de produção não ia embora, eu não ficava tranquila com medo de que algo desse errado, porque as cobranças no dia seguinte seriam terríveis.

O assistente administrativo enfatizou o processo burocrático da área, 0 acúmulo de tarefas e a falta de apoio do gestor em situações simples do dia a dia:

Era difícil de passar até o cartão de crédito do cliente, tudo precisa de uma autorização, e ao invés do gerente facilitar ele dificultava a situação. Eu fazia o financeiro, a expedição e ajudava chefe do administrativo com as notas fiscais de entrada. Eles foram tirando pessoas da área e ficou tudo acumulado, e ainda cobravam rapidez e agilidade, a gente ficava refém dos processos [...]. Um dia eu passei tanto nervoso que eu tive manchas vermelhas da cabeça aos pés e fui parar no hospital (ENTREVISTA, assistente administrativo 7 anos de empresa).

Quando questionados da gestão de pessoas na pequena empresa que trabalham atualmente, os principais pontos ressaltados foram: autonomia e confiança por parte do proprietário, reconhecimento do bom trabalho, tranquilidade, maior espaço para novas ideias, facilidade de comunicação e proximidade com o 
proprietário. Tem-se, assim, a PME como opção ao trabalhador qualificado e não apenas ao mais desqualificado, como apontado anteriormente pelo IBGE.

As pequenas empresas, apesar de não terem, por vezes, um setor específico e estratégico de recursos humanos, possuem facilidades e práticas simples que fazem do trabalho mais satisfatório para seus empregados.

O vendedor que trabalhou por 10 anos na multinacional relatou que o principal motivo de ter aceitado trabalhar na pequena empresa foi a proximidade com o proprietário:

Você está fazendo um bom trabalho é o dono que está vendo, você não precisa de um trampolim para as informações chegarem lá em cima. Não é só salário, o reconhecimento conta muito. Na empresa que eu trabalhava eu me empenhava muito no relacionamento com as pessoas, na manutenção de um clima saudável, na motivação dos que estavam ao meu redor e eu nunca tive um reconhecimento por isso nessa empresa, as vezes eu tirava dinheiro do meu bolso para fazer churrasco para a meninada do pátio em forma de agradecer o empenho e ajuda deles com as vendas, isso porque nem comissão eu ganhava, mas era uma característica minha, e o gerente nunca falou: 'Oh, legal o que você fez pelo pessoal'. É coisa simples, por exemplo, a primeira vez que organizei uma confraternização nessa empresa que eu estou trabalhando, o dono mandou uma mensagem no meu celular, me agradecendo pelo o empenho e falando que isso era muito importante para a equipe e que ele estava feliz com a minha iniciativa. (ENTREVISTA, vendedor 10 anos de empresa).

A coordenadora de PCP, por sua vez, relatou: "na empresa que eu trabalhava se eles te mandassem plantar bananeira de ponta cabeça você tinha que fazer de qualquer jeito, hoje eu converso com o dono sobre uma situação difícil, ele procura me entender e me apoia no que for preciso".

O operador de pátio, hoje, é gerente de logística em uma pequena empresa e diz: "estou há 7 meses nessa empresa e já subi de cargo duas vezes, o dono reconheceu o meu trabalho e me deu a oportunidade. O salário é praticamente 0 mesmo, mas no outro lugar eu demorei 17 anos para consegui-lo".

As necessidades da organização, especialmente no que se refere a manter as pessoas, parecem guiar as decisões dos donos do negócio, que então adaptam suas estratégias.

SILVA, L. F. A.; SCHEFFER, A. B. B. A gestão de pessoas nas micro e pequenas empresas: comparando experiências. Revista de Empreendedorismo e Gestão de Pequenas

Empresas, v.4, n.3, 2015. 
O vendedor que trabalhou na multinacional por 4 anos, hoje é gerente comercial de uma pequena empresa e reconhece que a proximidade do dono com os funcionários é um diferencial, a gestão de pessoas é feita não só com relação ao trabalho: "procuro conhecer cada funcionário, até os problemas pessoais, e se estiver no seu alcance ele os ajuda".

Novamente, percebe-se a questão de uma gestão mais próxima e tal proximidade, tão citada entre os entrevistados, mostra claramente a predominância de laços afetivos entre os dirigentes e os funcionários que, por vezes, ultrapassam o domínio organizacional, seja na concessão de favores ou em certa transgressão de hierarquias, vinculando-se ao paternalismo e associando-se às práticas de gestão de pessoas.

As principais vantagens e desvantagens de se trabalhar na pequena e grande empresa, pela visão dos entrevistados podem ser observadas a seguir:

Quadro 5 - Relação de vantagens e desvantagens apresentadas pelos entrevistados com experiência de trabalho em grandes e MPEs

\begin{tabular}{|c|c|c|c|}
\hline \multicolumn{2}{|c|}{ Grande Empresa } & \multicolumn{2}{c|}{ Pequena Empresa } \\
\hline Vantagens & Desvantagens & Vantagens & Desvantagens \\
\hline Super Estrutura & RH distante & Salário compatível & Estrutura Limitada \\
\hline $\begin{array}{c}\text { Viagens pela } \\
\text { empresa }\end{array}$ & $\begin{array}{c}\text { Poucas possibilidades de } \\
\text { altos cargos }\end{array}$ & $\begin{array}{c}\text { Proximidade com o } \\
\text { proprietário }\end{array}$ & $\begin{array}{c}\text { Ausência de Política } \\
\text { Salarial }\end{array}$ \\
\hline Visão Sistêmica & $\begin{array}{c}\text { Muita dependência do } \\
\text { superior imediato }\end{array}$ & Qualidade de vida & Permanência no local \\
\hline Contatos & Alto nível de Estresse & Autonomia & - \\
\hline Status & Alta Burocracia & Reconhecimento & - \\
\hline - & & Maior chance de um bom \\
trabalho aparecer & \\
\hline
\end{tabular}

Fonte: As autoras (2015).

De maneira geral, com as 18 (dezoito) entrevistas realizadas, pôde-se verificar a ausência de políticas definidas de gestão de pessoas na pequena empresa. A política salarial é feita de forma compatível ao segmento do mercado, 
mas não existe um plano sistemático de carreira. As promoções, muitas vezes, são através do salário e vão sendo feitas de acordo com o desempenho dos funcionários. Entretanto, apesar de não estar esquematicamente alinhada às estratégias de negócio, ela se mostrou mais eficiente no que tange à gestão de pessoas, pelo número reduzido de funcionários e pela pouca complexidade de sua estrutura.

Por fim, é preciso dizer que a proximidade do proprietário da empresa com os funcionários mostrou ser um fator importante para a boa condução das práticas gerenciais.

\section{Considerações finais}

A discussão em torno do fator humano nas organizações tem levado a uma série de estudos sobre a gestão estratégica de pessoas, sobretudo, em grandes organizações em razão de sua complexidade estrutural. A conjuntura do Brasil mostra um grande número de pequenas empresas responsáveis por mais da metade dos empregos gerados no país. Contudo, existe uma retórica que privilegia o sucesso do trabalhador nas grandes organizações.

A fim de lançar um olhar mais crítico a tal retórica, o presente trabalho buscou relatar as práticas de gestão de pessoas, que é um fator importante para o trabalhador, em ambos cenários: a pequena e a grande empresa.

As práticas de gestão de pessoas adotadas pelas pequenas empresas foram pensadas e baseadas nas vivências de seus proprietários, em suas trajetórias e em seus sentimentos que guiam a gestão como um todo. O recrutamento, a seleção, remuneração e a busca por informações em prol do negócio, se mostraram bastante particulares e fruto da construção social que a empresa está inserida.

Ao se recrutar um novo funcionário, não são levadas em consideração apenas as qualidades e competências do candidato, mas, principalmente, buscam lealdade e comprometimento. A gestão de pessoas ficou bastante caracterizada pela paternidade, envolvimento do empresário com o funcionário em uma gestão individualizada, construção de laços afetivos e promoção de práticas motivacionais 
(benefícios recreativos). Em contrapartida, espera-se do funcionário a dedicação e lealdade, não podendo descartar o caráter estratégico deste tipo de gestão.

Diante de toda pesquisa realizada, em vários aspectos, a pequena empresa mostrou-se mais favorável ao trabalhador do que a grande empresa, tendo a gestão de pessoas como aliada para seu sucesso. Apesar do estresse excessivo e das falhas de gestão de pessoas, a grande empresa foi citada como importante fonte de experiência e de desenvolvimento do indivíduo enquanto profissional.

Outro aspecto encontrado, foi a dificuldade do empreendedor em buscar informações ou soluções nas literaturas acadêmicas, cursos de graduação e pósgraduação para ajudá-los na condução e gestão de seus negócios. Entretanto, a principal fonte de informação, segundo os entrevistados, é informal, por meio da rede de contatos com concorrentes e fornecedores, indicando a construção de saberes por meio da experiência e da construção social da empresa, desconsiderada pela literatura na constituição das teorias administrativas.

A maior parte dos entrevistados revelou que a decisão de saída do grande empreendimento se deu pela negligência por parte daqueles que ocupavam cargos estratégicos, no que tange ao ato gerir pessoas. Passaram a valorizar o que mais caracteriza os pequenos empreendimentos, como o reconhecimento por parte do superior, a autonomia na execução das tarefas, uma relação mais familiar no ambiente de trabalho e uma gestão de pessoas mais próxima.

As práticas constituídas de gestão de pessoas nos pequenos empreendimentos mostraram-se em contínuo movimento de adaptação ao contexto, sendo mais produto de relações e de histórias vividas pelos gestores do que de processos racionais formulados com base nos conhecimentos disponíveis no mercado.

Tal constatação não deve ser, entretanto, encarada como algo negativo, de pouco valor, mas sim pensada como estratégica, inserida em uma lógica e um contexto particular que exige do empresário maior flexibilidade, rapidez e destreza, para reter e motivar seus funcionários em meio à concorrência acirrada e dinâmica do mercado globalizado. Tais práticas, apesar de não serem sistematizadas, proporcionam, na maioria das vezes, um maior conforto, fidelidade e satisfação ao trabalhador, conforme constatado na pesquisa realizada.

SILVA, L. F. A.; SCHEFFER, A. B. B. A gestão de pessoas nas micro e pequenas empresas: comparando experiências. Revista de Empreendedorismo e Gestão de Pequenas

Empresas, v.4, n.3, 2015. 
Mesmo que este estudo destaque o valor das práticas construídas no cotidiano do trabalho, evidenciando dimensões que são por vezes esquecidas ou desvalorizadas no campo da gestão, entende-se que o crescimento de tais empresas implica em um desenvolvimento constante dos seus dirigentes e funcionários, bem como o aprimoramento de técnicas e modos de gestão.

Em síntese, é importante ressaltar que a dinâmica que acontece em determinados momentos das MPEs é essencial. Isto é, não se pode desconsiderar toda uma aprendizagem que lá ocorre, mesmo tendo em vista a necessidade de profissionalização dessas empresas.

\section{Referências:}

ALVES, Z. M. M. B.; SILVA, M. H. G. F. D. da. Análise qualitativa de dados de entrevista: uma proposta. Paidéia (Ribeirão Preto), n. 2, p. 61 - 69, 1992.

ALVIM, L. R. de A.; ALVIM, S. J. T. Estudo dos Efeitos do Pacote de Benefícios Sociais sobre a Motivação e Produtividade dos Colaboradores em uma Empresa do Interior. In.: VIII CONGRESSO VIRTUAL BRASILEIRO DE ADMINISTRAÇÃO CONVIBRA ADMINISTRAÇÃO, 8, 2011. Disponível em: <http://www.convibra.com.br/upload/paper/adm/adm_3438.pdf>. Acesso em 01 set. 2014.

BAER, W. A Economia Brasileira. 2. ed. São Paulo: Editora Nobel, 1996.

BARROS, A. N. de; CRUZ, R. C.; XAVIER, W. S.; CARRIERI, A. de P.; LIMA, G. C. O. Apropriação dos Saberes Administrativos: um olhar alternativo sobre o desenvolvimento da área. RAM, Rev. Adm. Mackenzie (Online), v. 12, n. 5, 2011.

BRASIL. Lei $n^{\circ} 7.256$, de 27 de novembro de 1984. Estabelece normas integrantes do Estatuto da Microempresa, relativas ao tratamento diferenciado, simplificado e favorecido, nos campos administrativo, tributário, previdenciário, trabalhista, creditício e de desenvolvimento empresarial. Diário Oficial da União. Brasília, DF, p. 17521,28 nov. 1984.

BRASIL. Ministério do Trabalho e Emprego. Cadastro geral de empregados e desempregados: Evolução de Empregos do CAGED - EEC. Disponível em: <http://bi.mte.gov.br/eec/pages/consultas/evolucaoEmprego/consultaEvolucaoEmpre go.xhtml\#relatorioSetorEco>. Acesso em: 24 ago. 2014.

SILVA, L. F. A.; SCHEFFER, A. B. B. A gestão de pessoas nas micro e pequenas empresas: comparando experiências. Revista de Empreendedorismo e Gestão de Pequenas

Empresas, v.4, n.3, 2015. 
CARDON, M. S.; STEVENS, C. E. Managing human resources in small organizations: What do we know? Human Resource Management Review, v. 14, n. 3, p. $295-323,2004$.

CERTEAU, M. A invenção do cotidiano: artes de fazer. Petrópolis: Vozes, 1998.

FISCHER, A. L. Um resgate conceitual e histórico dos modelos de gestão de pessoas. In: FLEURY, Maria T. (org). As pessoas na organização. São Paulo: Ed. Gente, 2002.

FREITAG, B.; OHTSUKI, C.; FERREIRA, M. A. A Gestão de Talentos no campo da Gestão de Pessoas: tema emergente? In.: XXXVI ENCONTRO NACIONAL DA ANPAD - ENANPAD, 36, 2012, Rio de Janeiro. Anais...: Rio de Janeiro: ANPAD, 2012.

GOMES, M. T. S. As Mudanças No Mercado de Trabalho e o Desemprego em Presidente Prudente/Sp - Brasil. Barcelona: Revista Eletrônica de Geografia e Ciências Sociais, v. 6, n. 119, 2002.

GOULART, I. B. Estudos exploratórios em psicologia organizacional e do trabalho In: GOULART, I. B.; SAMPAIO, J. dos R. (orgs.). Psicologia organizacional e do trabalho: teoria, pesquisa e temas correlatos. São Paulo: Casa do Psicólogo, 2002.

IBGE, INSTITUTO BRASILEIRO DE GEOGRAFIA E ESTATÍSTICA. As Micro e Pequenas Empresas Comerciais e de Serviços no Brasil 2001. Rio de Janeiro: IBGE, 2003.

LASTRES, H. M. M.; CASSIOLATO, J. E.; MACIEL, M. L. Pequena Empresa: Cooperação e Desenvolvimento Local. Rio de Janeiro: Relume Dumará, 2003.

LEGGE, K. Human Resource Management. New York: Palgrave, 2005.

MARLOW, S.; PATTON, D. Managing the employment relationship in the small firm: Possibilities for human resource management. International Small Business Journal, v. 11, n. 4, p. 57 - 64, 1993.

RAM, M. Managing autonomy: Employment relations in small professional service firms. International Small Business Journal, v. 17, n. 2, p. 1 - 13, 1999.

SILVA, L. F. A.; SCHEFFER, A. B. B. A gestão de pessoas nas micro e pequenas empresas: comparando experiências. Revista de Empreendedorismo e Gestão de Pequenas

Empresas, v.4, n.3, 2015. 
SEBRAE, SERVIÇO BRASILEIRO DE APOIO ÀS MICRO E PEQUENAS EMPRESAS. Fatores Condicionantes e Taxas de Sobrevivência e Mortalidade das Micro e Pequenas Empresas no Brasil 2003-2005. 2007.

SEBRAE, SERVIÇO BRASILEIRO DE APOIO ÀS MICRO E PEQUENAS EMPRESAS. Classificação das Micro e Pequenas Empresas de Acordo com o Número de Funcionários. 2013.

SEBRAE, SERVIÇO BRASILEIRO DE APOIO ÀS MICRO E PEQUENAS EMPRESAS. Análise do Emprego: Brasil Fevereiro/2014. Brasília: UGE/NA - NEP, 2014. p. 60.

TANURE, B.; EVANS, P.; CANÇADO, V. As Quatro Faces de RH: Analisando a Performance da Gestão de Recursos Humanos em Empresas no Brasil. RAC Revista de Administração Contemporânea, v. 14, n. 4, art. 2, p. 594 - 614, 2010.

TONELLI, M. J.; PLIOPAS, A. L.; FONSECA, P. Doces Práticas para Matar: Como Profissionais de Recursos Humanos e Demissores Descrevem a Construção de Práticas Organizativas em Demissão e Downsizing. In: XXIX ENCONTRO DA ANPAD - ENANPAD, 29, 2005, Brasília. Anais... ANPAD, Brasília, 2005.

WOOD JUNIOR, T. Gestión de recursos humanos en Brasil: Tensiones e hibridismo. Academia - Revista Latinoamericana de Administración, n. 33, p. 68-80, 2004.

WOOD JUNIOR, T.; TONELLI, M. J.; COOK, B. Colonização e Neocolonização da Gestão de Recursos Humanos no Brasil (1950-2010). Revista de Administração de Empresas, v. 51, n. 3, p. 232 - 243, 2011.

SILVA, L. F. A.; SCHEFFER, A. B. B. A gestão de pessoas nas micro e pequenas empresas: comparando experiências. Revista de Empreendedorismo e Gestão de Pequenas Empresas, v.4, n.3, 2015. 